\title{
TRUDEAU SANATORIUM
}

The board of trustees, under the presidency of Dr. J. Burns Amberson, has reluctantly decided that Trudeau Sanatorium will close on December 1,1954 . With a capacity of 180 beds, fewer than 70 have been occupied in recent months, which has meant an annual loss of about 125,000 dollars from the endowment fund of 3 million dollars.

One's thoughts inevitably go back to the days of Edward Livingston Trudeau, who graduated in medicine at the College of Physicians and Surgeons, New York, in 1871, and shortly afterwards, at the age of 26 , contracted pulmonary tuberculosis. "The treatment of tuberculosis was but a meditation on death" in those days, but he tried horse riding and strenuous open-air exercise, as had been prescribed for him. His general health steadily deteriorated, and in 1873 he went up to a remote part of the Adirondack Mountains, not so much to obtain a cure, but because he felt that his days were numbered and wanted to spend his few remaining months hunting and fishing among the mountains and lakes he had known in his youth.

Trudeau regained much of his health and vigour, and by 1876 a trickle of tuberculous patients began to be referred to him at Saranac Lake. In 1885 the Adirondack Cottage Sanatorium, later called the Trudeau Sanatorium, was founded. The world-wide reputation which it subsequently gained was due to the consistently high standard of treatment given to its patients and the alert mentality of its medical staff. In 1915, the year of Trudeau's death, the Trudeau School of Tuberculosis was founded by Dr. E. R. Baldwin, Medical Director, for the instruction of postgraduate students.

Dr. G. M. Meade, the present Medical Director, attributes the decline in the number of patients to a variety of causes. New drugs and surgical methods have reduced the length of sanatorium treatment, more patients are being treated at home and in out-patient clinics, the disease is being diagnosed more often at an early stage, and many more free State sanatoria are available. Dr. Francis B. Trudeau, son of the founder, feels that his father would regard the closing of Trudeau Sanatorium as a victory for the methods and ideas he and his staff always held, and which contributed materially to lessening the misery this scourge has laid upon mankind.

The Saranac Laboratory, which was founded by Trudeau and has always formed such an important part of the institution, is unaffected by the recent decision and will continue, probably on an expanded scale, to be the nucleus of the Trudeau Foundation. 